\title{
ОСОБЕННОСТИ ПРЕПОДАВАНИЯ УЧЕБНОГО ПРЕДМЕТА «ОСНОВЫ РЕЛИГИОЗНЫХ КУЛЬТУР И СВЕТСКОЙ ЭТИКИ» В РОССИЙСКИХ ШКОЛАХ
}

\section{FEATURES OF TEACHING THE SUBJECT "FOUNDATIONS OF RELIGIOUS CULTURES AND SECULAR ETHICS" IN RUSSIAN SCHOOLS}

Yu. Goroshko

Summary: The article discusses the prerequisites for the introduction of the subject "Foundations of Religious Cultures and Secular Ethics" as mandatory in primary school. The functions of the teacher and parents in the implementation of a new subject are revealed. Culturological and communicative methodological approaches to teaching it are analyzed.

Keywords: school education, moral education, religious education, teaching of religious cultures.
Ц ель статьи - выявить специфические особенности внедрения и изучения относительно нового для российской системы образования мировоззренческого предмета «Основы религиозных культур и светской этики», обобщить опыт его преподавания в российских школах.

Предмет «Основы религиозных культур и светской этики» (далее -ОРКСЭ) был введен с 2012/2013 учебного года во всех четвертых классах общеобразовательных учреждений России. Этому предшествовал эксперимент по внедрению указанного предмета в ряде регионов с 2009 года. В процессе эксперимента преподавание предмета велось в четвертой учебной четверти четвертого класса и первой учебной четверти пятого класса. В настоящее время предмет ОРКСЭ преподается на протяжении всего учебного года в четвертом классе в объеме тридцати четырех часов, то есть один час в неделю.

Несмотря на то, что предмет ОРКСЭ уже не первый год является обязательной частью общеобразовательной программы, по-прежнему остаются проблемы, связанные с разработкой его содержания, методов преподавания и кадровой подготовки. В связи с этим, изучение специфики внедрения и накопленного опыта преподавания предмета ОРКСЭ являются актуальными в настоящее время.

Практика изучения религиозных культур в школе не ограничивается Российской Федерацией. В странах Ев-
Горошко Юлия Николаевна

К.ф.н., Крымский республиканский институт постдипломного педагогического образования,

г. Симферополь

julg13@mail.ru

Аннотация: В статье рассмотрены предпосылки введения предмета «0сновы религиозных культур и светской этики» как обязательного в начальной школе. Раскрыты функции педагога и родителей в реализации нового предмета. Проанализированы культурологический и коммуникативный методологические подходы в его преподавании.

Ключевые слова: школьное обучение, духовно-нравственное воспитание, религиозное образование, преподавание религиозных культур.

ропы и США образовательные системы также включают подобные предметы. Отличительной особенностью является то, что в зарубежных странах данная традиция сложилась исторически, эволюционно [1]. В Советском Союзе религия была полностью удалена не только из системы образования, но и из жизни общества в целом. После распада Советского Союза феномен религиозного возрождения становится актуальным и для нашей страны.

В России исследования уровня религиозности населения, проводимые ВЦИОМ, зафиксировали рост числа верующих с 57\% в 1991 г. до 74\% в 2001 г. Одно из наиболее компетентных современных социологических исследований религиозности в России проводилось службой «Среда» в 2012 году. По его результатам только 13\% россиян заявляют, что «не верят в Бога», остальные же считают себя религиозными.

Однако наряду с возрождением православия и других традиционных российских религий отмечается рост нетрадиционной и деструктивной религиозности. Для обозначения религиозных движений, представляющих опасность для личности, вводят термин «деструктивные культы» - «группы и организации, которые используют неэтичные техники манипулирования для вербовки и удержания своих членов, имеют тенденцию прямо или косвенно осуществлять контроль мыслей, чувств и поведения своих приверженцев» [Цит. по: 8]. Деструктивные культы невротизируют своих адептов, внушают им 
чувство вины, страх перед наказанием, блокируют их базовые потребности, наносят вред физическому и психическому здоровью. В результате человек попадает в зависимость от группы и ее лидера, теряет способность принимать самостоятельные решения, оказывается изолирован от семьи и друзей, подвергается эксплуатации и мошенническим манипуляциям его имуществом. Поддержка традиционной религиозности является барьером от распространения нетрадиционных деструктивных религиозных движений.

Также введению предмета ОРКСэ как общеобязательного в учебных заведениях Российской Федерации способствовали следующие социокультурные факторы:

- Потребность возвращения воспитательного компонента в систему образования, формирование у молодого поколения устойчивой системы ценностей на основе российских традиций патриотизма, любви к семье, гражданской солидарности.

- Опасности информационного общества: бесконтрольное распространение информации, которая создает многочисленные риски и может причинить вред физическому, психическому и нравственному развитию ребенка. Формирование устойчивой системы ценностных ориентиров у детей является барьером, способным защитить от опасного виртуального контента.

- Кризис института семьи, который выражается в распространении нетрадиционных форм брака (гражданский, гостевой, виртуальный, полигамный), нежелании молодых людей вступать в брак и заводить детей (установки чайлд-фри), увеличении количества неполных семей. Также можно отметить большое количество неблагополучных семей, неуважительные отношения в семье, проблему домашнего насилия.

- Индивидуализация и атомизация российского общества. Утрата социальной солидарности и доверия. После распада Советского Союза коллективизм сменяется на индивидуализм, причем, в крайних его проявлениях в виде эгоизма и потребительства. Люди оказываются неспособными на совместную продуктивную деятельность, руководствуются исключительно эгоистическими устремлениями личной выгоды.

- Рост экстремистских настроений и проявлений интолерантности в российском обществе, в том числе в молодежной среде. Появление радикальных объединений, пропагандирующих насилие по отношению к людям другой национальности, вероисповедания, убеждений [2].

Цель предмета ОРКСЭ заключается в формировании у школьников системы духовных ценностей, готовности к нравственному поведению, знаний о различных культурных и религиозных традициях и уважения к ним, развитие способности к диалогу с представителями других культур и мировоззрений.

Введение курса ОРКСЭ в четвертом классе является целесообразным, поскольку младший школьный возраст - это наиболее благоприятный, сензитивный период для нравственного воспитания детей [6]. Также начальная школа является важным этапом социализации, а изучение предмета ОРКСЭ помогает формированию навыков социального взаимодействия.

Несмотря на рост религиозности населения России и изменение отношения в обществе к религии, недавнее атеистическое прошлое дает о себе знать: введение предмета ОРКСЭ встречает ряд трудностей, непонимание его целей и содержания со стороны учителей и родителей.

Можно отметить сложности кадрового обеспечения предмета. В данном случае имеет значение не только уровень знаний педагога, но и его мировоззренческая позиция. Приверженность учителя нетрадиционным, деструктивным формам религиозности или явно выраженное негативное отношение к религии делают затруднительным преподавание ОРКСЭ [10]. Главные задачи педагога в данном случае - формирование российской гражданской идентичности и поддержка духовной традиции семьи, а не навязывание своего мировоззрения учащимся. В преподавании ОРКСЭ педагог должен руководствоваться культурологическим подходом, быть внимательным и толерантным, чтобы не допустить негативных оценок тех религиозных традиций, к которым он не принадлежит. В данном случае на педагога ложится большая ответственность, он становится «проводником, который транслирует духовные основания и нравственные ценности» [3].

Для родителей достаточно сложной задачей является выбор учебного модуля ОРКСЭ. Религиозные родители опасаются, что педагог будет недостаточно компетентен в вопросах веры и может исказить содержание религиозной традиции. Неверующие родители предполагают, что на уроках ОРКСЭ детей будут обращать в религию. Однако, чаще всего, родители просто не имеют представления о содержании предмета ОРКСЭ, его целях и значении.

Практика показывает, что, как правило, выбирается лишь один из модулей ОРКСЭ для всех учеников. Родительские собрания, связанные с обсуждением нового предмета проводятся формально. Многие родители даже не подозревают о возможности выбора [7].

В течение года перед проведением собрания, на котором будет выбираться модуль ОРКСЭ, педагог должен знакомить родителей с содержанием всех модулей, но при этом ни в коем случае не давать своих рекомендаций в отношении выбора. Для того чтобы помочь родителям 
сделать правильный осознанный выбор рекомендуется проведение открытых уроков по предмету ОРКСЭ, приглашение на родительское собрание тех родителей, чьи дети уже изучают данный предмет [9].

Курс ОРКСЭ предполагает активное взаимодействие с родителями. Это касается не только выбора учебного модуля, но и дальнейшее участие в образовательном процессе. Можно выделить два основных направления работы с родителями в рамках реализации предмета OPKCЭ:

1. Психолого-педагогическое просвещение родителей. Данное направление включает такие формы работы как: консультации (индивидуальные и тематические), родительские собрания, педагогические практикумы.

2. Вовлечение родителей в учебно-воспитательный процесс в рамках предмета ОРКСЭ. Взаимодействие с родителями позволяет расширить содержание предмета и придать ему личностный смысл [11]. Многие домашние задания по предмету организованы таким образом, что предполагают обсуждение вместе с родителями нравственных вопросов. Родители помогают детям в работе над проектами по темам ОРКСЭ. Также возможно участие родителей в экскурсиях и мероприятиях по предмету.

Отличительной особенностью предмета ОРКСЭ является его интегративный характер. Он включает знания из разных областей: истории, литературы, обществознания, религиоведения, культурологии, философии, этики. Задачей предмета является систематизация этих знаний, структурирование иерархии духовных ценностей в сознании учеников [4]. Предмет ОРКСЭ дает представление не только о духовных ценностях и религиозных идеях, но знакомит и с культурой повседневности - традициями, ритуалами, языком, бытом людей, жилищем, характером труда и досуга, В связи с этим, в рамках курса ОРКСЭ целесообразно включение этнографического материала и разработка регионального компонента [5].

Все модули курса ОРКСЭ и конфессиональные и не конфессиональные носят светский, культурологический характер. Преподавать предмет ОРКСЭ могут только учителя, прошедшие необходимую подготовку на курсах повышения квалификации. Не допускается преподавание данного предмета священнослужителями, представителями религиозных организаций. Учитель может пройти аккредитацию в религиозной организации и получить удостоверение о готовности преподавать курсы по данной религиозной культуре, но такая аккредитация не является обязательной для допуска к преподаванию предмета ОРКСЭ.

К основным принципам реализации курса относятся - свобода совести и вероисповедания, учет разнообразия мировоззренческих подходов, межконфессиональное сотрудничество, учет запросов граждан на изучение их детьми основ религиозной культуры.

Предмет ОРКСЭ носит личностный характер, ориентирован на внутренний мир школьника, знакомство с самим собой, прививает навыки нравственного самоанализа [5]. В преподавании необходимо учитывать личный опыт учеников, исходить из тех проблем, с которыми они неизбежн[о сталкиваются: национализм, ксенофобия, нетерпимость в разных ее проявлениях [7]. Предмет ОРКСЭ является важным ресурсом для формирования толерантности у детей и феномена доверия в обществе в целом [12].

Культурологический подход является главным в преподавании предмета ОРКСЭ. В рамках данного методологического подхода ученики осваивают национальные и религиозные традиции и ценности как формы выражения культуры. Предмет ОРКСЭ носит светский характер и не предполагает религиозного обращения и участия в религиозных ритуалах.

Также при изучении ОРКСЭ используется коммуникативный подход: предполагается активное обсуждение разных точек зрения и проблем, формирование уважительного отношения к позиции другого, умение говорить и слушать. В процессе изучения предмета развиваются коммуникативные компетенции учеников, формируется основа для толерантного отношения к представителям разных религиозных традиций и мировоззрений.

Таким образом, можно выделить следующие особенности преподавания ОРКСЭ: важность не только предметной компетентности педагога, но и его личностной позиции в отношении религии и курса ОРКСЭ, активное участие родителей в образовательном процессе, культурологический характер курса, недопустимость религиозного обращения также как и религиозной интолерантности, ориентация на формирование системы духовных ценностей школьника.

\section{ЛИТЕРАТУРА}

1. Башелханов А.Ю. Предмет «0сновы религиозных культур и светской этики» в российских школах // Педагогический имидж. - 2016. - №1 (30). C.23-29.

2. Горошко Ю.Н. Учебно-методическое пособие для слушателей дополнительной профессиональной программы повышения квалификации «Актуальные 
вопросы преподавания предмета «Основы религиозных культур и светской этики (ОРКСЭ)» в общеобразовательных организациях». - Симферополь: 000 «Антиква», 2021. -128 c.

3. Кильдяшова Т.А., Сибирцева Ю.А. К вопросу изучения религиозных культур в рамках современного российского школьного образования // Научные ведомости. Серия: Философия. Социология. Право. Вып. 3. - 2015.

4. Костюкова Т.А. Диалог культур: толерантность в национальных и конфессиональных отношениях (опыт организации современной жизни народов (ибири) / под ред. Г.И. Петровой. Томск: Центр ксерокопирования и ризографии «ЧП Кнышева Л.Н.», 2002.

5. Костюкова Т.А. Влияние содержания образования на воспитание доверия и согласия школьников (на примере предметной области «духовно-нравственная культура народов России») // Вестник Томского государственного университета. - 2018. - № 435. - С. $195-201$.

6. Монсонова А.Р. Учебный предмет «Основы религиозных культур и светской этики» как фактор социализации младших школьников // Вестник Кемеровского государственного университета. - 2015. - №3 (63), Т.3. - С. 19-21.

7. Ожиганова А.А. Религия в школе: анализ учебных пособий по курсу «0сновы религиозной культуры и светской этики» // Отечественная и зарубежная педагогика. - 2015. - С.82-99.

8. Сафронов А.Г. Психология религии. - К.: Ника-Центр, 2002. - 224с.

9. Теплова Е.Ф. Методологические проблемы в преподавании курса ОРКСЭ и пути их преодоления // Альманах «Этнодиалоги». - 2015. - №2 (49). C. 136-151.

10. Теплова Е.Ф. ОРКСЭ - новый модульный курс в современной школе // Альманах «Этнодиалоги». - 2013. - №2 (43). - С. 105-114.

11. Формы и методы работы с родителями // статья по ОРКСЭ (4 класс). - URL: https://nsportal.ru/nachalnaya-shkola/orkse/2017/01/27/formy-i-metody-rabotys-roditelyami (дата обращения: 05.09.2021)

12. Шапошникова Т.Д., Горбачева Т.М., Костюкова Т.А. Изучение влияния предметной области «духовно-нравственная культура народов России» на формирование у современной молодежи доверия и согласия // Человек и образование. 2018, №2 (55), С. 189-194.

с Горошко Юлия Николаевна (julg13@mail.ru).

Журнал «Современная наука: актуальные проблемы теории и практики»

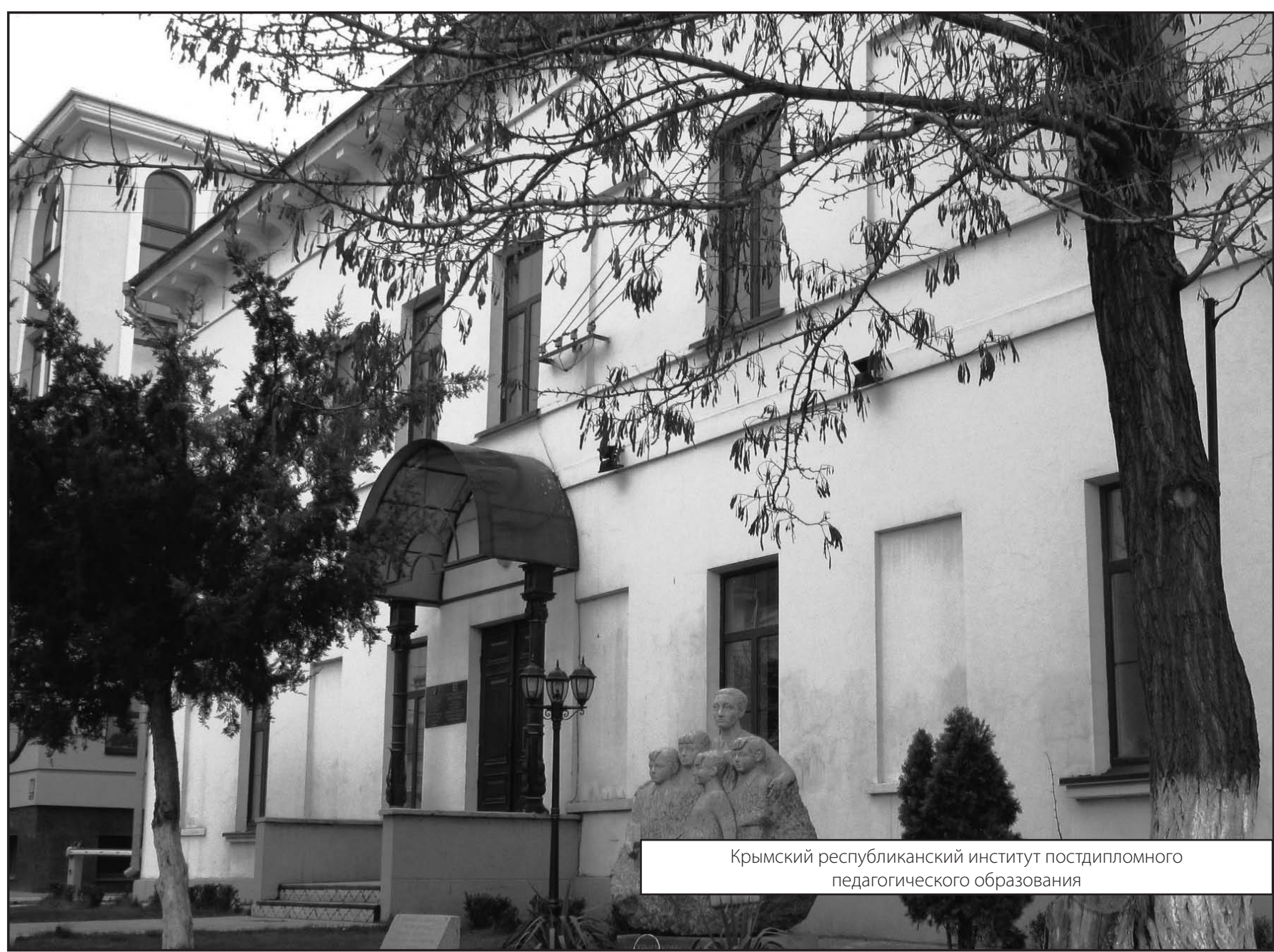

